\title{
The Influence of Entrepreneurship on Resource Bricolage: The Moderating Effect of Moral Leadership-A Case Study of Owners of Small and Medium Enterprises in Taiwan
}

\author{
Wei-Shang Fan \\ Associate Professor \\ Department of Business Administration \\ Nanhua University, Chiayi, Taiwan \\ Kuo-Chung Huang \\ Professor \\ Department of Business Administration \\ Nanhua University, Chiayi, Taiwan \\ Ping-Yu Chiang \\ Ph.D. Student \\ Department of Business Administration \\ Nanhua University, Chiayi, Taiwan
}

\begin{abstract}
Summary
This study was conducted withowners of small and medium enterprises (SMEs) in Taiwan as the research subjects. Survey data werecollected from 236 SME owners, andexploratory and confirmatory analysis on the reliability and validity of the datawere performed, followed bya hierarchical regression analysis. The results indicated that (1) SME ownerswith higher levels ofentrepreneurshipskills would be more actively engaged in resource bricolage to alleviate the problems and limitations facing the SMEs; (2) SME owners with a higher degree of moral leadership would be more supported for their resource bricolage behavior; (3) SME ownersusing their entrepreneurshipskills to perform resource bricolage would be subject to a negative moderating effect of their own moral leadership, that is, the lower the degree of moral leadership, the more effective the resource bricolage, which implies that when SME ownersareperformingresource bricolage, they may focus on onlysolving the problems and restrictions facing their SMEs while failing to pay attention to moral concerns in the process of resource bricolage. The findings in this study demonstrate a negative moderating effect of moral leadership in SME owners on the relationship between entrepreneurship and resource bricolage when SME owners are faced with resource scarcity and restrictions.
\end{abstract}

Keywords: SME owners, Entrepreneurship, Moral Leadership, Resource Bricolage

\section{Introduction}

According to the World Competitiveness Yearbook2019 published by the International Institute for Management Development (IMD) in Switzerland, Taiwanese enterprises have displayed increased competitiveness, achieving the greatest improvement in "business efficiency"- a competitiveness factor, and performing well in the assessment indicators of "entrepreneurship" and "sense of social responsibility"-namely,practicing excellent entrepreneurshipand having a strong sense of social responsibility. Entrepreneurship has always playedan important role in organizational and economic growth (Burgelman, 1983; Covin\&Slevin, 1991; Lumpkin \& Dess, 1996).The long-established entrepreneurial culture and thriving industrial activities in Taiwan have always been important drivers for the growth of Taiwanese enterprises and development of the Taiwanese economy (Tsai\& Wen, 2006). Previous studies such as those by Storeyand Johnson (1987), and BaljeandWaasdorp (2001) indicate that new small enterprise ventures are more likely to create employment opportunities in society compared to big enterprises, and that entrepreneurs with entrepreneurship and innovative skills are an important factor for driving a country's progress and economic growth. However, resource scarcity is an issue facing the owners of small and medium enterprises (SMEs). Baker and Nelson (2005) established three elements in a theoretical bricolage model-makedo, the combination of resources for new purposes, andresources at hand.It is possible to use these elements to overcome resource scarcity and environmental constraints, and even achieve resource construction, constraint conversion, and innovation in adversity (Hsiao et al.,2017). 
Moreover, An et al. (2018) also pointed out that enterprise leaders can identify new opportunities by organizingresource bricolage activities, asresource bricolage is an element that can effectivelydrive enterprises-not only by overcoming resource constraints but also by motivating enterprises to take initiatives for innovation and strategy update, so as to enhance the ability of enterprises to bear risks. These studies indicate that based on subjective entrepreneurship, enterprise leaders may organize, reconstruct, and experience resource learning activities, create subjective knowledge based on materials at hand, transform and rebuild the capability ofmaking do with resources at hand, and restructuring resource utilization, so as to achieve resource innovationand overcome problems as well as constraints. However, the effect of moral leadership in enterprise leaders on resource bricolage is unclear. Previous studies have emphasized that moral leadership can promote employees'moral behavior,as moral leaders serve as role models strongly characterized by honesty, trustworthiness, and integrity (Treviño, Hartman, \& Brown, 2000). When individuals trust their ability to meet moral requirements through moral self-regulation, they are likely to demonstrate moral behavior (Hannah, Avolio, \& May, 2011). Enterprise owners - the top leaders of enterprises, should take on a moral leadership role, and their decision-making and implementation processes will determine whether the performance of resource bricolage is grounded on moral goodness to overcome the problems of resource scarcity and constraints,oris just making do with resources to overcome the constraints.

Given the above context, this study aims to provide insight into three aspects: (1) the correlation between entrepreneurship, moral leadership, and resource bricolage in SME owners; (2) the relationship between entrepreneurship, moral leadership, and resource bricolage in SME owners; (3) the moderating effect of moral leadership in SME owners on the relationship between entrepreneurship and resource bricolage.

\section{Literature overview}

\subsection{Entrepreneurship}

Entrepreneurship is a common feature of many SME owners, and is still playing the utmost important role in organizational and economic growth and development. To date, studies by Taiwanese scholars on entrepreneurship generally fall into three categories - (1) studies on capital-increasing factors, compensation factors, and investment activities of venture companies; (2) studies on intra-enterprise entrepreneurial and innovative mechanisms; (3) studies on entrepreneurial behavior and process (e.g., Tsai\& Wen, 2006). These studies point out that the concept of entrepreneurshipinvolves the autonomy of individuals or enterprises in undertaking innovative behavior, stating that leaders - whether individuals or organizations - are capable of making their own decisions informulatingvisions and goals; innovativeness refers to the supporting of new ideas, the adoption of new problem-solving methods, and the degree of creativity; empirical studies on enterprises emphasize enterprise proactiveness - namely,enterprises taking initiatives to connect with markets, and enterprise risk-taking - namely,enterprises being willing to input resources and be able to bear the consequence of failure. In addition, a study by Salunke et al. (2013) indicated that entrepreneurship is usually adopted in a manufacturing context to conduct innovative research while such practice is inadequate to capture the unique operational characteristics in service enterprises, and thereby argued that in particular, adaptiveness is needed for greater interaction with clients. Adaptiveness refers to the customization of products and services that companies provide to meet clients' needs. Compared torelatively large enterprises, SMEs and new ventures are often subject toresource scarcity due tothe small organizational size and lack of self-owned funds (Gilmoreet al., 2001; Carson \&Cromie, 1990). However, given the fact thatSME ownersdo not stop enterprise development just because of resource scarcity, it is of practical importance to study the process and performanceof resource bricolage.

\subsection{Bricolagetheory and its management application}

Bricolage theory was originally proposed by French anthropologist, Lévi-Strauss (1967), who observed that craftsmen are good at using tools or materials at hand - even irrelevantones if they are the only choice-when performing a project, or preservingmaterials that are not needed for current use but would be used in the future, and coined the concept of bricolage. Baker and Nelson (2005) definedbricolage as the application of a combination of existing resources to new issues and opportunities. This definition has three key elements-(1) makingdo, which refers to a behavioral tendency, namely, a tendency for active involvement in problem-solving processes or opportunities rather than for hesitation on whether to create a feasible outcome using the resources at hand; (2) the combination of resources for new purposes, which refers to a combination of different application modes and a new use of resources rather than the originally planned or used resources; (3) the resources at hand, their use of which represents a costeffective resource-utilization mode without wastage of resources. Following this concept and definition, Tu and Hung (2012) demonstrated that bricolage itself has multiple connotations-(1)from the aspect of resource, bricolage implementors must develop the resources at hand; (2) from the aspect of action, the implementors make do with and reorganize the resources at hand for new use; 
(3) from the aspect of purpose, bricolage refers tosolving problems and exploringfeasible opportunities so as to overcome the obstacles of resource scarcity and environmental constraint (Hsiao, 2017).

Bricolagetheory has also been adopted in the research field of entrepreneurship and business management, and has proven to be very useful in explaining various phenomena. For example, Baker and Nelson (2005) found that it can explain why some SME owners or entrepreneurs can create something out of nothing. Chen et al. (2010) adopted the concept of bricolage to explore the development of innovative productsin entrepreneurial teams.Salunke et al. (2013) demonstrated that service entrepreneurship and bricolage can influence the sustainable competitive advantage of project-oriented enterprises through service innovation. Wu et al. (2017) revealed that bricolage has impacts on the development speed and creativity of new products with the ability toaccelerate innovation.Hsiao et al. (2017), based on the concept of bricolage, proposed a power-inverse model, arguing thatlow-power actors would achieve innovation in adversity if they were able to leverage the resources at hand. As shown above, when faced with resource scarcity, individuals and organizations can increase resource utilization through bricolage, which not only reducesthe wastage of resources but also represents a type of innovation. However, it is unclear howa moral leadership role would affect the decision-making process of enterprise owners when intending to perform resource bricolage.

\subsection{Effect of the moral leadership role}

The concept of moral leadership can be applied to any type of organization (Potipiroon\& Ford, 2017).Bandura's (1986) social cognitive theory emphasized that individuals can use self-regulating mechanisms to encourage themselves to believe that they are capable of achieving goals. Consequently, when individuals under self-regulation believe that they are capable of meeting moral requirements, they are likely to demonstrate moral behavior (Hannahet al., 2011). SME owners as the highest representatives of the enterprisesplay a moral leadership role, and each decision-making and implementation process should not only maximize enterprise profits and save costs but also ensure that the profits are not at the expense of social costs or at the expense of others' benefits. Due to the insufficiency of internal resources when facing a changing market and environment, SME owners sometimes take measures to cope with present situations by violatingmoral codes or relevant laws in order to overcome some constraints. For example, there are still concerns about the frequent incidences of food safety crises and immoral commercial practices. A series of major moral scandalsnot only hurts the corporate image of business organizations but also undermines the confidence of the general public in the government's ability to handle these incidents.

Many studies in the past have attempted to understand the role of moral leadership (e.g., Lee et al.,2017; Schaubroeck et al., 2012; Brown \&Treviño, 2006). Moral leadership is defined as the demonstration of a normatively appropriate conduct through personal actions and interpersonal relationships, and the promotion of such conduct to followers through two-way communication, reinforcement, and decision-making (Brown et al., 2005). Therefore, moral leaders are not only honest and trustworthy decision makers but also those who adhere to moral principles and integrity even under enormous external pressure, andare able to encourage followers to practice responsible moral behavior by setting moral standards and expectations (Treviño et al., 2000). In this context, this study proposed that subjective entrepreneurship in enterprise leaders involves autonomous decision-making, and that individuals and organizations may have various effects onresource bricolage under the self-regulating mechanism of moral leadership, that is, when faced with resource constraints and environmental changes, individuals and organizations continue to learn, transform, and reshape their abilities to make do with and reorganize resources through their own past experiences, so as to achieve resource innovationand overcome problems and constraints.

\section{Research methods}

\subsection{Research architecture and hypotheses}

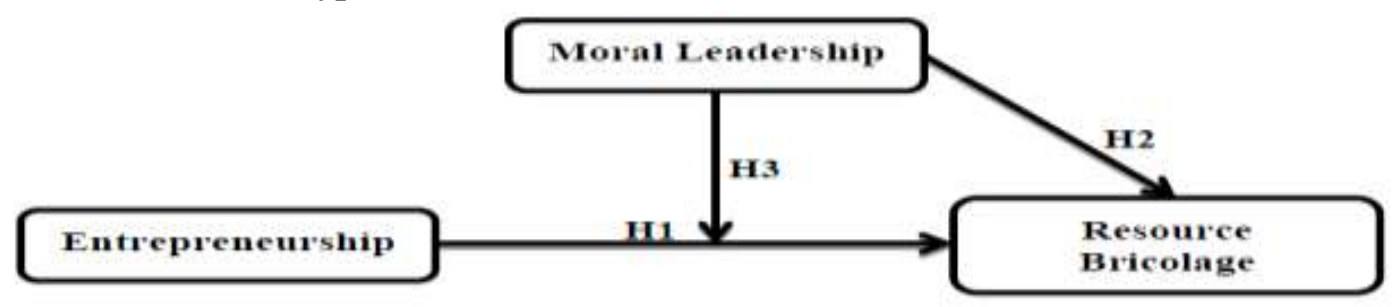

Figure 1. Research architecture

Hypothesis 1: Entrepreneurship has a positive and significant relationship with resource bricolage Hypothesis 2: Moral leadership has a positive and significant relationship with resource bricolage Hypothesis 3: Moral leadership has a moderating effect on the relationship between entrepreneurship and resource bricolage 


\subsection{Research samples and data}

This study was conducted withTaiwanese SME ownerswho were selected through purposive sampling. Through the Extramural Guidance Association for Students under the Taiwan Ministry of Education, questionnaire surveys were conducted under the coordination of SME owners-established student assistance groups.In order to ensure that the surveys were responded to by SME owners themselves, the questionnaires were administered through anetwork of the SME ownerswho established student assistance groups, that is, the supply chain and social networks of the SME owners were used. For example, SME owners in the construction or manufacturing industry conduct transactions with upstream raw-material manufacturers and downstream product-selling companies, as well as with enterprises supplying property, plant, and equipment (PPE) and also provide equipment maintenance. The questionnaires were administered in the period of March 2018 to August 2018. A total of 294 questionnaires were administered, with 253 handed in. After exclusion of 17 invalid questionnaires, there were 236 valid questionnaires, resulting in an effective response rate of $80.27 \%$. Relevant descriptive statistics of control variables of the survey subjects, as elaborated in Table 1, indicated that 163 SME owners were male accounting for $69.1 \%$ of the total subjects, and 74 were female accounting for $30.9 \%$; the highest level of education wasjunior college education/university education, held by 152 SME owners accounting for $64.4 \%$; most $(n=101)$ of the SMEswere agedbetween 3-5 years, accounting for 42.8\%; most $(n=104)$ of the SMEs had less than 30 employees, accounting for $44.1 \%$.

Table 1. Basic information

\begin{tabular}{c|ccc}
\hline $\begin{array}{c}\text { Basic } \\
\text { information }\end{array}$ & Answer option & Number & Percentage (\%) \\
\hline Gender & Male & 163 & 69.1 \\
\cline { 2 - 4 } & Female & 73 & 30.9 \\
\hline $\begin{array}{c}\text { Level of } \\
\text { education }\end{array}$ & $\begin{array}{c}\text { Senior high } \\
\text { school/vocational } \\
\text { school (and below) }\end{array}$ & 59 & 25.0 \\
\cline { 2 - 4 } & $\begin{array}{c}\text { Junior } \\
\text { college/university }\end{array}$ & 152 & 64.4 \\
\cline { 2 - 4 } & Master (and above) & 25 & 10.6 \\
\hline \multirow{2}{*}{$\begin{array}{c}\text { Enterprise } \\
\text { age }\end{array}$} & Below 3 years & 43 & 18.2 \\
\cline { 2 - 4 } & 3-5 years & 101 & 42.8 \\
\cline { 2 - 4 } & 6-10 years & 79 & 33.5 \\
\cline { 2 - 4 } & Above 10 years & 13 & 5.5 \\
\hline \multirow{2}{*}{$\begin{array}{c}\text { Enterprise } \\
\text { size }\end{array}$} & Less than 30 persons & 104 & 44.1 \\
\cline { 2 - 4 } & $31-50$ persons & 102 & 43.2 \\
\cline { 2 - 4 } & $51-100$ persons & 27 & 11.4 \\
\cline { 2 - 4 } & $101-200$ persons & 3 & 1.3 \\
\hline
\end{tabular}

Note: $n=236$

\subsection{Study variables and evaluation}

Entrepreneurship (EN) was the independent variable in this study, which was defined as the ability of SMEs to conduct autonomous decision-making, solve problems and organize resources with innovative ideas, adapt to the market, as well as bear necessary risks. Entrepreneurship was measured using four questions following Salunke et al. (2013), and Lumpkin and Dess (1996).Moral Leadership (ML) was a moderator variable, which was defined as the demonstration of normatively appropriate conduct of SME owners through personal actions and interpersonal relationships, and the promotion of such conduct among followers through two-way communication, reinforcement, and decision-making. Moral leadership was measured using three questions following Lee et al. (2017),Potipiroon and Ford (2017), and Browen et al. (2005).Resource Bricolage (RB) was the dependent variable, which was defined as make do bySME owners with resources at hand for resource combination and restructuring to overcome various problems and constraints. Bricolage was measured using three questions following Salunke et al. (2013), and Baker and Nelson (2005), as shown in Table 2. Measurement of the variables was conducted on a7-point Likert scale, with scores ranging from a minimum of 1 point to a maximum of 7 points, which corresponded to "strongly disagree," "disagree," "slightly disagree," "neither agree nor disagree,"“"slightly agree,"“agree," and“"strongly agree," respectively. 


\section{Research results}

\subsection{Reliability and validity analysis}

First, the recovered questionnaires weresubject to exploratory factor analysis (EFA) with the three study variables:EN (4 items),RB (3 items), and ML (3 items). The Kaiser-Meyer-Olkin (KMO) valuesof the three study variables were in the range of $0.692-0.823(\mathrm{p}<0.001)$ with statistical significance, and the eigenvalues werein the range of 2.3653.083.The cumulative explanatory variation was 77.074-79.779\%. Cronbach's $\alpha$ coefficients represent the degree of internal consistency of factors within a test, which were in the range of $0.865-0.901$, all greater than the generally acceptable minimum of 0.70 (Nunnally, 1978). Second, confirmatory factor analysis (CFA) was performed to further test the composite reliability (CR) and convergent validity (CV) of the four study variables. The CR values were in the range of 0.863-0.904, all greater than 0.6 (Bagozzi\& Yi, 1988).Factor loadingswere in the range of 0.705-0.939, all greater than 0.7 (Nunnally, 1978). Average variation extracted (AVE) was in the range of 0.677-0.702, greater than the 0.5 cut-off limit (Fornell\&Larcker, 1981). These CFA results indicated that the study variables had goodCRand CV, as elaborated in Table 2.

Further, discriminant construct validity was evaluated for the three study variables (EN, ML, BE).A three-factor theoretical model was to be adopted in this study; a two-factor model was constructed by merging the independent variable EN and the moderator variable ML into one variable while keeping the same dependent variable BE; a singlefactor model referred to treating the three study variables as the same construct. CMIN stands for Chi-square $\left(\chi^{2}\right)$ and is used to evaluate the goodness-of-fit of the model to the data. When CMIN is 0, it indicates that the data is fully fitted. DF refers tothe degree of freedom. Given that a Chi-square test is susceptible to sample size,Bagozzi and Yi (1988) recommendedusing the ratio of Chi-square to degree of freedom (CMIN/DF).RMSEA refers to the root mean square error of approximation. A smaller RMSEA value represents a better model fit, with the range of $0.05<$ RMSEA $<0.08$ widely accepted to indicate a good model fit (McDonald \& Ho, 2002); a smaller value of SRMR, namely, standardized root mean square residual, indicates a better model fit, with SRMR values less than 0.05 suggesting a good fit (Jöreskog\&Sörbom, 1989). CFI (comparative fit index) is between 0-1, and the closer the index is to 1, the better the model fit; CFI represents the deviation of the presumed model from the central chi-square distribution, and a CFI value above 0.95 is presently recognized as indicative of a good model fit (Bentler, 1995); TLI (Tucker-Lewis index) is between $0-1$, and the closer the index is to 1 , the better the model fit, with a TLI value above 0.9 indicating a good model fit (Bentler\&Bonett, 1980).

As shown in Table 3, the three-factor theoretical model was tested by discriminant validity CFA $\left(\chi^{2}=40.393\right.$, $\mathrm{df}=32$; $\mathrm{CMIN} / \mathrm{DF}=1.262 ; \mathrm{RMSEA}=0.033 ; \mathrm{SRMR}=0.028 ; \mathrm{CFI}=0.994 ; \mathrm{TLI}=0.992)$, and the results indicated that the model had a better fit compared to the two-factor model $\left(\chi^{2}=278.554, \mathrm{df}=34 ; \mathrm{CMIN} / \mathrm{DF}=8.193 ; \mathrm{RMSEA}=0.175\right.$; SRMR $=0.092 ; \mathrm{CFI}=0.834 ; \mathrm{TLI}=0.781)$, and the single-factor model $\left(\chi^{2}=460.848, \mathrm{df}=35 ; \mathrm{CMIN} / \mathrm{DF}=13.167\right.$; RMSEA $=0.228$; SRMR $=0.117$; CFI $=0.711$; TLI $=0.629)(\mathrm{Wu}$ et al., 2017; Liang at al., 2012). In short, the threefactor theoretical model displayeda good fit and discriminant validity. Moreover, as shown in Table 4, the square root of AVEof each constructwas between 0.823 and 0.838 , and above the correlation coefficients between various constructs, indicating that each construct met the discriminant criteria and had discriminant validity (Hair et al., 2006).

Table 2. Reliability and validity verification of the measures

\begin{tabular}{lcc}
\hline \multicolumn{1}{c}{ Question } & $\begin{array}{c}\text { CFA factor } \\
\text { loading }\end{array}$ & Eigenvalue \\
\hline EN $(\alpha=0.901 ; \mathrm{CR}=0.904 ; \mathrm{AVE}=0.702)$ & & 3.083 \\
1.I can determine the future direction by myself & 0.800 & 0.884 \\
2.I can understand and bear the inevitable risks in starting a new business & 0.884 \\
3.I can propose innovative business concepts to create profits & 0.778 & 2.393 \\
4.I can anticipate changes in the external environment and have proper coping & & \\
measures & 0.705 & \\
EL $(\alpha=0.865 ; \mathrm{CR}=0.869 ; \mathrm{AVE}=0.691)$ & 0.939 & 2.365 \\
1.I set an example of moral behavior in my decision/action & 0.834 & \\
2.My behavior is consistent with the stated value & & \\
3.I regard honesty and integrity as important personal values & 0.793 \\
RB $(\alpha=0.872 ; \mathrm{CR}=0.863 ;$ AVE $=0.677)$ & 0.857 \\
1.I use resources at hand to solve various problems in an innovative manner & 0.817 \\
2.I explore new values of the resources at hand to improve resource utilization & \\
3.I combine and reorganize resources by challenging traditional business practices & \\
\hline
\end{tabular}


註: $n=236$

Table 3. CFA of discriminant validity

\begin{tabular}{lcccccccc}
\hline \multicolumn{1}{c}{ Factor structure } & $\chi^{2}$ & df & $\Delta \chi^{2}$ & CMIN/DF & RMSEA & SRMR & CFI & TLI \\
\hline Three-factor model (EN, ML,R B) & 40.393 & 32 & & 1.262 & 0.033 & 0.028 & 0.994 & 0.992 \\
Two-factor model (EN+ML, RB) & 278.554 & 34 & $238.161^{* * *}$ & 8.193 & 0.175 & 0.092 & 0.834 & 0.781 \\
Single-factor model (EN+ML+RB) & 460.848 & 35 & $420.455^{* * *}$ & 13.167 & 0.228 & 0.117 & 0.711 & 0.629 \\
\hline
\end{tabular}

Note: $n=236 ;{ }^{* * * * *} \mathrm{p}<0.001$

Table 4.Averages, standard deviations, Pearson correlation coefficients, and discriminant validities

\begin{tabular}{lccccc}
\hline \multicolumn{1}{c}{ Construct } & Average & Standard deviation & A & B & C \\
\hline A(EN) & 4.368 & 1.110 & $(0.838)$ & & \\
B(ML) & 4.162 & 1.008 & $0.499^{* * *}$ & $(0.832)$ & \\
C(RB) & 4.137 & 1.098 & $0.528^{* * *}$ & $0.474^{* * *}$ & $(0.823)$ \\
\hline
\end{tabular}

Note: $n=236$; the value on the diagonal is the square root of the average variation extracted (AVE) of this potential variable and should be greater than the correlation coefficients between various constructs. $\mathrm{p}<0.05 ;{ }^{* * *} \mathrm{p}<0.01 ;{ }^{* * *} \mathrm{p}$ $<0.001$

\subsection{Descriptive Statistics and Relevant Analysis}

Table 4 shows the mean value, standard deviation, Pearson's correlation coefficient, and square root of the AVE for each variable. The results indicate significant positive correlations between Entrepreneurship and Moral Leadership (r $=0.499, \mathrm{p}<0.001)$, Entrepreneurship and ResourceBricolage $(\mathrm{r}=0.528, \mathrm{p}<0.001)$, Moral Leadership and Resource Bricolage $(r=0.474, p<0.001)$, The results are consistent with the preliminary inference of this study, as they show that there are indeed positive and significant relationships between each variable. Thus, the hypotheses are found to be initially supported.

\subsection{Difference analysis}

An independent-sample T test was performed on gender, and a Scheffe's post-hoc comparison test was performed on other demographic itemsfor single-factor ANOVA, as demographic characteristics play an important role in the statistics of each structure. First, Table 5 shows that the level of entrepreneurship skills inmale SME owners was significantly greater than in female SME owners. Entrepreneurship skills decreased significantly with a decrease in education level, in the order of master's education and above < junior college/university education < senior high school/vocational school education and below. Entrepreneurship skills inboth SMEs aged more than 10 years and those between 6-10 years were significantly greater than in SMEs aged less than 3 years. Second, moral leadership in SME owners with master's education and above was significantly greater than in those with senior high school/vocational school education and below; moral leadership was significantly greater in SMEs aged 6-10 years than in SMEs aged 35 years. Finally, resource bricolage of SME owners was significantly greater in SMEs aged 6-10 years than in SMEs aged 3-5 years.

Table 5. Difference Analysis

\begin{tabular}{cccc}
\hline Control variable & Entrepreneurship & Moral leadership & Resource bricolage \\
\hline Gender & $1>2$ & $\mathrm{~N}$ & $\mathrm{~N}$ \\
Education level & $3>2>1,2>1$ & $3>1$ & $\mathrm{~N}$ \\
Enterprise age & $4>1,3>1$ & $3>2$ & $3>2$ \\
Enterprise size & $\mathrm{N}$ & $\mathrm{N}$ & $\mathrm{N}$ \\
\hline
\end{tabular}

Note: Gender: (1) Male, (2) Female; Education level: (3) Master (and above), (2) Junior college/University, (1) Senior high school/vocational school (and below);Enterprise age: (4) 10 years or more, (3) 6-10 years, (2) 3-5 years, (1) less than 3 years

\subsection{Hypothesis verification}

Variance inflation factor (VIF) analysis was adopted to test multicollinearity.The maximum VIF was 1.368, below the cut-off value of 10 (Neter, William, \&Kutner, 1985), indicating the absence of significant collinearity.The research hypotheses were separately verified using hierarchical regression analysis. 
The analysis results, as presented in Table 6, show that in model 1, the independent variable EN had a significant and positive relationship with the dependent variable $R B$, with a regression coefficient of $0.528,\left(p<0.001, R^{2}=0.279\right)$, suggesting that hypothesis 1 could not be rejected.

In model 2,the moderator variable ML had a positive and significant relationship with the dependent variable RB, with a regression coefficient of $0.280\left(\mathrm{p}<0.001, \mathrm{R}^{2}=0.337\right)$, suggesting that hypothesis 2 could notbe rejected. In model 3, theinteraction term $\mathrm{EN} *$ ML had a negative moderating effect with a regression coefficient of $-0.149\left(\mathrm{p}<0.01, \mathrm{R}^{2}=\right.$ 0.357 ), suggesting that hypothesis 3 could not be rejected. $\mathrm{R}^{2}$ represents the explanatory power of a regression model, and $\Delta \mathrm{R}^{2}$ refers to the difference in $\mathrm{R}^{2}$ between two models. If $\Delta \mathrm{R}^{2}$ is significantly positive, it means that the addition of new variables helps to improve the explanatory power of the model. When the variable ML was included in model 2, the overall explained variation of RBwasincreased $\left(\Delta R^{2}=0.059\right.$, and significant), indicating that the inclusion of ML in the model was meaningful; after the inclusion of the interaction term in model 3 , the overall explained variation of RBwas further increased $\left(\Delta \mathrm{R}^{2}=0.020\right.$, and significant), indicating that there was a significant moderating effect on resource bricolage of SME owners. The regression coefficient of model 3 was -0.149 with statistical significance, indicating that the ML of SME owners had a negative moderating effect on the relationship between EN and RB(Fig. 2).

Table 6.Hierarchical regression analysis of the moderator variable

\begin{tabular}{llll}
\hline & Dependent variable & \multicolumn{3}{c}{ Resource Bricolage } \\
Independent variable & Model 1 & Model 2 & Model 3 \\
\hline EN & $0.528^{* * * * *}$ & $0.388^{* * * * * *}$ & $0.362^{* * * * * *}$ \\
ML & & $0.280^{* * * *}$ & $0.253^{* * * *}$ \\
EN*ML & & & $-0.149^{* *}$ \\
$\mathrm{R}^{2}$ & 0.279 & 0.337 & 0.357 \\
$\Delta \mathrm{R}^{2}$ & & 0.058 & 0.020 \\
$\mathrm{~F}$ & & $59.330^{* * * *}$ & $43.013^{* * *}$ \\
\hline
\end{tabular}

$\mathrm{P}<0.05^{*}, \mathrm{P}<0.01^{* * *}, \mathrm{P}<0.001$

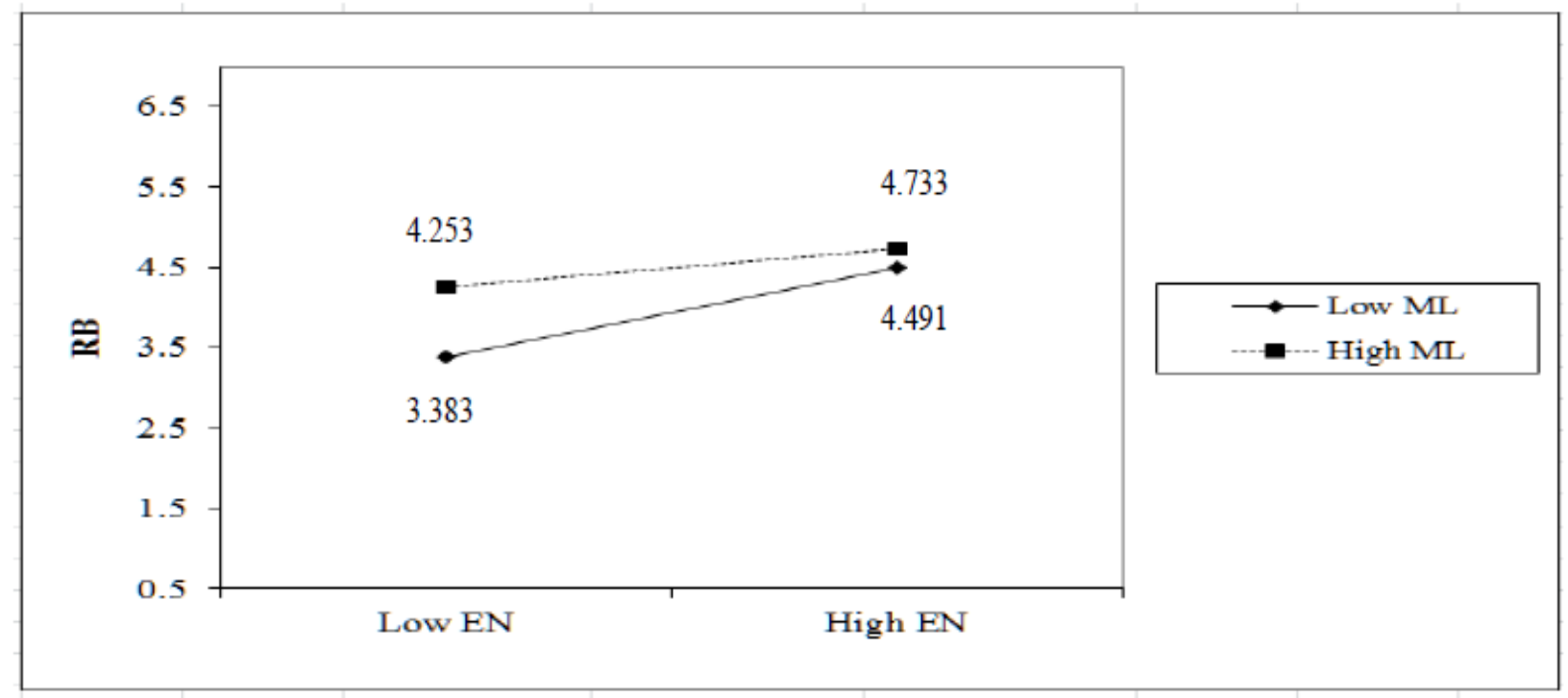

Figure 2: Moderating effect of moral leadership (ML) on the relationship between entrepreneurship (EN) and resource bricolage $(\mathbf{R B})$

\section{Conclusion}

In this study,questionnaire surveys were performed with 236 Taiwanese SME owners. Three hypotheses could not be rejected by confirmatory factor analysis. The regression analysis revealed that in the model of hypothesis 1 ,entrepreneurship had a positive relationship with resource bricolage $(0.528, \mathrm{p}<0.001)$, indicating that SME ownerswith a high degree of entrepreneurship would more proactively perform resource bricolage to overcome the problems and constraints facing the enterprises. For hypothesis 2, moral leadership had a positive relationship with resource bricolage $(0.280, \mathrm{p}<0.001)$, indicating that SME ownerswith a higher degree of moral leadership would be more supported for their resource bricolage behavior. 
For hypothesis 3, it was established that moral leadership had a moderating effect on the relationship between entrepreneurship and resource bricolage $(-0.149, \mathrm{p}<0.01)$, indicating that when SME ownerspracticeentrepreneurshipand perform resource bricolage, they would be affected by their own moral leadership; the negative moderating effect indicated that when SME owners have low moral leadership, resource bricolage would lead to more benefits. In other words, when performing resource bricolage, SME owners are likely to be only concerned about overcoming the company's own problems and restrictions without having moral concerns about the resource bricolage, which may damage the interests of other stakeholders or non-stakeholders (such as violating the Working Hours Act or causing damages to the ecological environment).

This study revealed how the moral leadership of SME owners would affect the relationship between entrepreneurship and resource bricolagewhen they are faced with resource scarcity and restriction. Moreover, the findings provided deeper insight into the self-regulating mechanism of moral leadership, a field less explored by previous studies on entrepreneurial management. This was a cross-sectional study based on the assumption that the relationship between independent and dependent variables would not change with time, and the metrics applied were all translated and adapted from those used by foreign scholars.Although the results of this study were shown to have good reliability and validity with many literature reports, the translated metrics applied may still be subject to cultural and semantic differences. Moreover, questionnaire-based data collection may introduce methodological errors, which was a limitation of this study.

Acknowledgment: The author would like to thank all the participating SME owners and director Li-Zhi Yang for their assistance, and is more grateful to Mr. Yu-Hao Lee and Miss Ru-Jun Liu for their assistance.

\section{References}

Min-Fen, T., \&Shih-Chang, H. (2002).Creating Something from Something: How ITRI EnactsB.B.C. Strategies to Transform the Technology Development Program.Journal of Management and Business Research, 29(3), 229254.

International Institute for Management Development (IMD), Lausanne, Switzerland.IMD World Competitiveness Yearbook 2019.https://www.ind.ch/wcy

Yi-Wen, C., Se-Hwa, W., \&Wei-Hsin, H. (2010). The Resource-based View of the Resource Bricolage and Value Creation for Innovative Product Development: A Case of "Taiwan Opens up the Wings."Journal of Technology Management, 15(2), 1-20.

Cheng-An, T., \&Chao-Tung, W. (2006).The Empirical Study of Corporate Entrepreneurship on Taiwan Enterprises.Journal of Technology Management, 11(4), 37-62.

Ruey-Lin, H., Su-Hua, O., \&Yen-Kuan, W. (2017). Making-do within Adversity: Resource Constraints as a Source of Innovation.Sun Yat-Sen Management Review, 25(1), 219-268.

Ruey-Lin, H., Su-Hua, O., \&Yun, S. (2017). Inversing the Powerful: The Process of Resource Construction through Bricolage.NTU Management Review, 27(4), 1-32.

An, W., Zhao, X., Cao, Z., Zhang, J.,\& Liu, H. (2018). How Bricolage Drives Corporate Entrepreneurship: The Roles of Opportunity Identification and Learning Orientation. Product Development and Management Association, 35(1), 49-65.

Baker, T., \&Nelson, R. E. (2005).Creating Something from Nothing: Resource Construction Through Entrepreneurial Bricolage.Administrative Science Quarterly, 50(3), 329-366.

Balje, S.,\&Waasdorp, P. (2001).Entrepreneurship in the 21st century. In Entrepreneurship in the Netherlands, New Economy: New SME owners! EIM Business \& Policy Research and the Ministry of Economic Affairs, 29-49.

Bandura, A. (1986). Social foundations of thought and action: A social cognitive theory. Englewood Cliffs, NJ: Prentice Hall.

Bentler, P. M., \&Bonett, D. G. (1980).Significance Tests and Goodness of Fit in the Analysis of Covariance Structures. Psychological Bulletin, 88(3), 588-606.

Bentler, P. M. (1995). EQS structural equations program manual. Encino, CA: Multivariate Software.

Brown, M. E.,Treviño, L. K., \&Harrison,D. A. (2005).Moral Leadership: A Social Learning Perspective for Construct Development andTesting. Organizational Behavior and Human Decision Processes, 97(2), 117-134.

Brown, M. E., \&Treviño,L. K. (2006).Moral Leadership: A Review andFuture Directions. Leadership Quarterly,17(6), 595-616.

Burgelman, R. A., (1983). Corporate Entrepreneurship and Strategic Management: Insights from a Process Study. Management Science, 29, 1349-1364. 
Carson, D., \&Cromie, S. (1990). Marketing Planning in Small Enterprises: A Model and Some Empirical Evidence. The Journal of Consumer Marketing, 7(3), 5-18.

Covin, J.G.,\&Slevin, D. (1991).A Conceptual Model of Entrepreneurship as Firm Behavior.Entrepreneurship Theory and Practice, 16(1), 7-25.

Gilmore, A., Carson, D., \& Grant, K. (2001).SME Marketing in Practice.Marketing Intelligence and Planning, 19(1), 611.

Hair, J. F., Black, W. C., Babin, B. J., Anderson, R. E., \& Tatham, R. L. (2006). Multivariate data analysis (6th ed.). New Jersey: Pearson Educational International.

Hannah, S. T., Avolio, B. J., \& May, D. R. (2011). Moral Maturation and Moral Conation: A Capacity Approach to Explaining Moral Thought and Action. Academy of Management Review, 36, 663-685.

Jöreskog, K. G., \&Sörbom, D. (1989). LISREL 7: A guide to the program and applications. Chicago: SPSS Inc.

Lee, D., Choi, Y., Youn, S., \& Chun, J-Uk. (2017). Moral Leadership and Employee Moral Voice: The Mediating Role of Moral Efficacy and the Moderating Role of Leader-Follower Value Congruence. Journal of Business Ethics, 141(1), 47-57.

Lévi- Strauss, C. (1967). The savage mind. Chicago, IL: University of Chicago Press.

Lumpkin, G.T.,\& Dess, G.G. (1996). Clarifying the Entrepreneurial Orientation Construct and Linking it to Performance. Academy of Management Review, 21(3), 135-172.

McDonald, R. P., \& Ho, M. R. (2002). Principles and Practice in Reporting Structural Equation Analysis. Psychological methods, 7, 64-82.

Salunke, S., Weerawardena, J., \& McColl-Kennedy, J. R. (2013).Competing Through Service Innovation: The Role of Bricolage and Entrepreneurship in Project-oriented Firms. Journal of Business Research, 66(8), 1085-1097.

Schaubroeck, J. M., Hannah, S. T., Avolio, B. J., Kozlowski, S. W., Lord, R. G., Treviño, L. K., Dimotakis, N.,\& Peng, A. C. (2012). Embedding Moral LeadershipWithin and Across Organization Levels. Academy of Management Journal,55(5), 1053-1078.

Storey, D., \& Johnson, S. (1987). Small and Medium-Sized Enterprises and Employment Creation in the EEC Countries: Summary Report, EC Commission,Programme of Research and Actions on the Development of the Labour Market Study, 85, 407.

Treviño, L. K., Hartman, L. P., \& Brown, M. (2000).Moral Person and Moral Manager: How Executives Develop a Reputation for Moral Leadership. California Management Review, 42, 128-142.

Wisanupong, Potipiroon, \& Michael, T. F. (2017). Does Public Service Motivation Always Lead to Organizational Commitment? Examining the Moderating Roles of Intrinsic Motivation and Moral Leadership. Public Personnel Management, 46(3), 211-238.

Wu, L., Liu, H.,\& Zhang, J. (2017).Bricolage Effects on New-product Development Speed and Creativity: The Moderating Role of Technological Turbulence. Journal of Business Research, 70, 127-135. 